\title{
BMJ Open Occurrence of depressive tendency and associated social factors among elderly persons forced by the Great East Japan Earthquake and nuclear disaster to live as long-term evacuees: a prospective cohort study
}

Yujiro Kuroda, ${ }^{1,2}$ Hajime Iwasa, ${ }^{1,3}$ Aya Goto, ${ }^{4}$ Kazuki Yoshida, ${ }^{5}$ Kumiko Matsuda, ${ }^{2}$ Yumi Iwamitsu, ${ }^{6}$ Seiji Yasumura ${ }^{1}$

To cite: Kuroda $Y$, Iwasa $\mathrm{H}$, Goto A, et al. Occurrence of depressive tendency and associated social factors among elderly persons forced by the Great East Japan Earthquake and nuclear disaster to live as long-term evacuees: a prospective cohort study. BMJ Open 2017;7:e014339. doi:10.1136/ bmjopen-2016-014339

- Prepublication history for this paper is available online. To view these files please visit the journal online (http://dx.doi org/10.1136/bmjopen-2016014339).

Received 11 0ctober 2016 Revised 16 May 2017 Accepted 16 June 2017

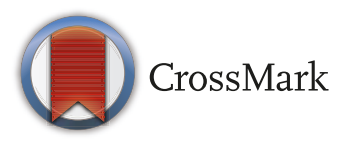

For numbered affiliations see end of article.

Correspondence to Dr Yujiro Kuroda; kuroday@fmu.ac.jp

\section{ABSTRACT}

Purpose This study examined the incidence of depression and associated factors among elderly persons from litate village after the March 2011 earthquake.

Method This was a prospective cohort study. As a baseline survey, in May 2010 a self-assessment Basic Checklist (BCL) was distributed to 1611 elderly villagers, of which 1277 responded. Of these respondents, 885 without a tendency to depression (69.3\%) were given a followup survey in May 2013. The BCL was used to assess depression tendency, instrumental activities of daily living (IADL), physical function, nutritional status, oral function, homeboundness, cognitive function and social activities. Univariate analysis was used to examine differences in risk between those with a presence of depression tendency (PDT) and those without (non-PDT) depending on demographic and BCL variables. Variables found to be significant were analysed by Poisson regression analysis. Results Of the 438 respondents in the second survey, $163(37.2 \%)$ showed depression tendency. PDT risk was significantly increased by female gender, age, history of diabetes and cognitive disorder. It was significantly reduced by increased IADL. Engagement in social activities decreased PDT risk in rental accommodation.

Discussion Renters faced a higher risk of PDT than persons evacuated in groups to purpose-built housing. The inclusion of social activities in the multivariate Poisson regression analysis weakened this effect. Female gender, a history of diabetes, reduced IADL and a tendency to cognitive disorder each independently affected PDT risk. These findings may inform future responses to earthquakes and the technical disasters that may accompany them.

\section{BACKGROUND}

The Great East Japan Earthquake of 11 March 2011 brought about enormous human and material damage due to the earthquake itself, the resulting tsunami and the accident at the Fukushima No. 1 Nuclear Power Plant.

\section{Strengths and limitations of this study}

- This cohort study examined the incidence of depression and associated factors among elderly persons from litate village after the March 2011 earthquake.

- The study used data collected before and after the disaster forced the whole village to evacuate, and the response rate was high owing to the participation of the local municipality. Therefore, the data are likely to reflect the characteristics of the affected areas and can be used in designing future victim support programme in the event of a future radiation disaster in another region.

- However, because the first survey was designed by the local municipality, it did not include sufficient variables related to depression.

Most of the damage was centred in Iwate, Miyagi and Fukushima Prefectures. Reported health effects included external wounds, circulatory diseases, pneumonia, psychological stress and cognitive function decline. ${ }^{1-3}$ The mid-term and long-term impacts have hindered daily life activities and potentially increased the number of elderly persons who require special care ${ }^{24}$ : the proportion of persons in need of long-term care in the year following the earthquake increased by $7.1 \%$ in the coastal regions of affected prefectures, compared with $3.7 \%$ in the interior regions of affected prefectures and $2.8 \%$ in unaffected prefectures. ${ }^{5}$

\section{Postdisaster depression}

Mental health effects were the most prominent public health consequence of the 1986 Chernobyl accident. ${ }^{6}$ The main effects 
were depression, anxiety, post-traumatic stress disorder, general distress and medically unexplained somatic symptoms. ${ }^{7}$ Overall, excess psychological morbidity in the first year after a disaster is around $20 \%{ }^{8}$ In general, the most important risk factors affecting mental health after disasters are the severity or scale of the disaster itself, personal vulnerability factors, and the degree of chaos and hardship after the disaster. ${ }^{9}$ Other possible vulnerability factors include female gender, low socioeconomic status, experience of severe disaster damage, major housing damage, poor social support, physical injury, history of mental illness, traumatic experience and proximity to the disaster site. ${ }^{10-13}$ The proportion of individuals with psychological distress after the disaster was far greater in a Fukushima health management survey $(14.6 \%)$ than in other areas affected by the earthquake and tsunami $(6.2 \%)$ or in the Japanese population under normal circumstances $(4.2 \%-4.4 \%) \%) .{ }^{11} 14$

Previous studies in the aftermath of disasters have demonstrated relationships between displacement and type of evacuation. ${ }^{15}$ They suggest that adverse psychological outcomes differ depending on the postdisaster housing experience, including geographic distance from the predisaster community, type of postdisaster housing, number of postdisaster moves and time spent in temporary housing.

\section{Depression among elderly persons}

Elderly persons frequently experience significant life events, including decline in physical function, health problems accompanying disease, changes in social responsibilities due to retirement from employment, loss from death of familiar persons and removal from familiar environments to live in care. These experiences may increase anxiety and loneliness or lead to depression or self-isolation. Non-Japanese research has linked insufficient social support with increased risk of death, poorer physical health and increased risk of depression, ${ }^{16} 17$ while Japanese research has linked it with depression among elderly people. ${ }^{18}$ Throughout the broad disaster regions affected by the March 2011 earthquake, many elderly people have experienced profound changes in their living environments, including separation from family and loss of work, and do not receive adequate social support. ${ }^{19}$ The disruption of social relationships among victims due to a disaster can exacerbate secondary traumas. ${ }^{20}$ Elderly persons who experienced the March 2011 disaster may therefore face a higher risk of depression than younger persons.

\section{The situation in litate village}

Iitate village, the subject of our study, was not directly affected by the earthquake, but the entire village was ordered to evacuate owing to contamination. In a 2012 survey, $65 \%$ of households reported that family members were living in two or more locations, and $23.4 \%$ that members were living in three or more locations. ${ }^{21}$ The local municipality considered evacuating the community to a single site, but resettlement had to meet villagers' needs of employment, schooling or avoiding restrictions on their living environment. As a result of dispersion, the total number of households, which was about 1700 before evacuation, increased to about 3300 after the members of these households had evacuated to various sites. Only $30 \%$ of the households evacuated intact, with many moving into rental accommodation. About $10 \%$ of the residents evacuated to a site outside the prefecture. Additionally, 42.7\% reported having few friends or acquaintances nearby and no real partners for communication, indicating limited availability of social support. The village lies in a mountainous farming area that supports flourishing agriculture, livestock and floriculture industries. Before the evacuation, it held regular community events favoured by women and young persons. ${ }^{22}$ Following the evacuation, however, many persons became unemployed or left the village permanently, causing a loss of motivation and disintegration of the local community. ${ }^{22}$ This dramatic decline in social networks caused concern about the villagers' mental health. Because evacuees living in temporary rental accommodation have fewer ties to other persons than those living in purpose-built temporary accommodation, they face a higher risk of depression.

Prior research has examined earthquakes' effects on mental health and depression in elderly persons; however, very few large-scale studies have examined elderly persons who have suffered a disaster or compared their lives before and after a disaster. Because elderly persons are particularly vulnerable in the event of a technical disaster, studying earthquakes' effect on their mental health is essential to developing effective support methodologies.

\section{Purpose}

This study examined the incidence of depression and associated factors among elderly persons from Iitate village after the March 2011 earthquake in different living arrangements. We examined the relationship between depression status and living environment (ie, rental or purpose built) to inform the development of support methods.

\section{METHODS \\ Participants}

This was a prospective study, and in May 2010, a self-assessment 'Basic Checklist' (BCL) was distributed to 1611 elderly persons (aged $\geq 65$ years) living in Iitate village. This baseline survey was conducted as a village government project to identify residents likely to require special care. There were 1277 respondents $(79.3 \%$ response rate). In May 2013, a follow-up survey polled the 885 persons $(69.3 \%)$ without a tendency to depression in the 


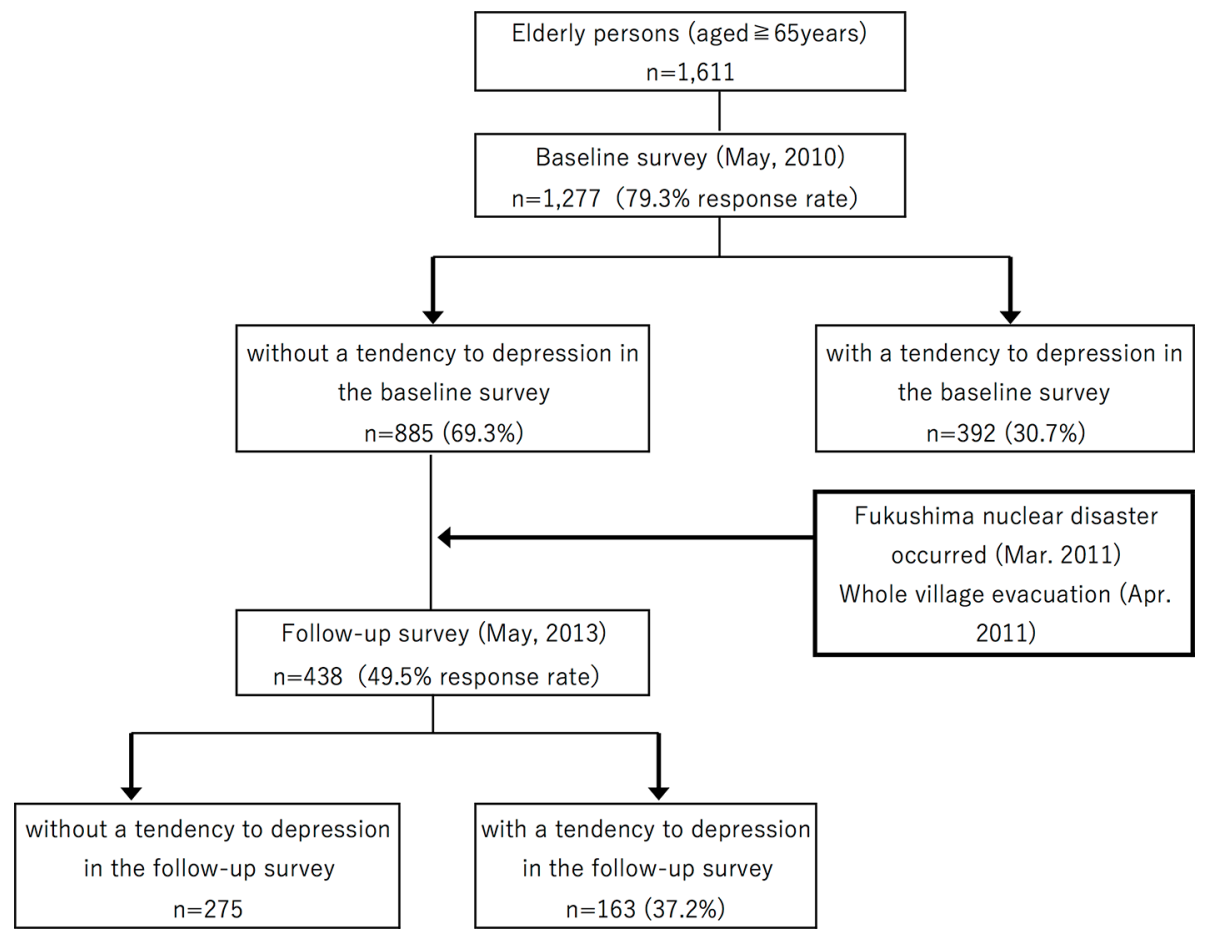

Figure 1 Flowchart of the participants through the study.

baseline study. The 438 respondents to this study became the subject of this study (figure 1).

\section{Variables}

\section{Outcome}

Depression was evaluated from 'depressive mood domain' drawn from the BCL. ${ }^{23} \mathrm{BCL}$ is a simple self-reporting yes/ no survey consisting of 25 questions regarding instrumental activities of daily living (IADL, three questions), social activities (two questions), physical functions (five questions), nutritional status (two questions), oral function (three questions), cognitive function (three questions) and depressive mood (five questions). ${ }^{24} 25$ This comprehensive questionnaire can assess the physical psychological, functional and social statues of non-disabled older adults in multiple domains. Difficulty with any question is counted as a score in the BCL, with a higher score in each domain of the checklist indicating higher risk of requiring support or care in that domain.

In depression mood domain, it asks the following questions with respect to the previous 2-week period: 'Is your life pretty full?' 'Do you still enjoy doing the things you used to do?' 'Do you think it is too much trouble to do the things you used to do?' 'Do you feel that you are a useful person who is needed by others?' 'Do you feel tired without any specific reason?' The BCL 'depression mood' is consistent with Depression and Suicide Screen. ${ }^{26}$ As an index of internal consistency, Cronbach's alpha for this scale was 0.719 .

\section{Predictors}

We drew information on baseline age, body mass index and disease history (ie, hypertension, heart disease, diabetes, osteoporosis or stroke) from the village health survey database.

The BCL subscales are used to assess IADL, social activities, physical function, nutritional status, oral function, homeboundness and cognitive function. ${ }^{27}{ }^{28}$ Following a scoring manual published by the Japan Ministry of Health, Labour and Welfare, we considered an item to indicate deterioration if the responses were as follows: 'physical function', $\geq 3$ of 5 items; 'nutritional status', 2 of 2 items; 'oral function', $\geq 2$ of 3 items; 'homeboundness', 1 of 1 item; and 'cognitive function', $\geq 1$ of 3 items. In addition to this, IADL scores are calculated as 0 (poor) to 3 (favourable), and social activities is considered as 'deterioration' when $\geq 1$ of 2 items applied.

We identified where evacuees were living during the follow-up survey from the village residents' register. Most evacuees were living in purpose-built accommodation (nine sites in Fukushima Prefecture), prefecture-rented temporary accommodation, nursing homes or hospitals. Excluding evacuees in nursing homes or hospitals, we distinguished between 'purpose-built accommodation' and 'rental accommodation'. Because evacuees living in rental accommodation have fewer ties to other persons than those living in purpose-built temporary accommodation, they face a higher risk of depression.

\section{Statistical analysis}

In the follow-up survey, items assessing 'depressive mood' were defined as examining "presence of depression tendency' (PDT), and the responses were sorted into PDT and non-PDT groups. To examine differences in risk between the two groups depending on demographic 
variables, IADLand BCL, we used the $\chi^{2}$ test for categorical variables and Student's t-test for continuous variables. Then, by using the variables found to be significant in the univariate analysis as explanatory variables, gender and age as adjustment variables, and PDT as the response variable, we carried out a Poisson regression analysis. We first evaluate crude prevalence ratio (PR) at first stage, then added items found to be significant in the above univariate analysis at second stage. Finally, we added social domain to examine its effect on evacuation residence site. All statistical analyses were conducted with SPSS Statistics for Macintosh, V.19.0 software.

\section{Ethical considerations}

This survey was conducted as part of a health programme of the health and welfare section of the Iitate village government. During a health examination, local government officials explained the nature of the survey and obtained the written consent of respondents. The Ethics Committee of Fukushima Medical University granted its consent (Examination No. 2609). This work was supported by JSPS KAKENHI Grant Number JP15K17296. The authors declare that they have no conflict of interest.

\section{RESULTS}

\section{Participant demographics}

The mean age of the participants, $59.8 \%$ of which were female (table 1), was 73.6 years (range: 66-89). By medical history, $44.5 \%$ of participants had hypertension, $8.7 \%$ had heart disease and $5.5 \%$ had diabetes. In the BCL risk assessment, $29.9 \%$ were at risk of requiring prevention or support for cognitive function, and $13.7 \%$ for homeboundness.

Using data from the initial survey, we compared individuals who participated in the follow-up survey $(n=438)$ with those who did not $(\mathrm{n}=447)$. By gender, $59.8 \%$ of participants and $59.3 \%$ of non-participants were female. Participants had a median age of 73.6 years (range: 66-91 years), and non-participants of 73 years (66-90 years) at baseline. Participants and non-participants had the following respective proportions of disease: hypertension, $44.5 \%$ vs $37.5 \%$; heart disease, $8.7 \%$ vs $7.3 \%$; diabetes, $5.5 \%$ vs $4.6 \%$; osteoporosis, $2.5 \%$ vs $2.1 \%$; and stroke, $3.0 \%$ vs $2.5 \%$. All differences were not significant $(\mathrm{p}<0.05)$ by the $\mathrm{X}^{2}$ test. Thus, there was no evidence of selective dropout due to poor health.

Table 1 Univariate Poisson regression results of postearthquake depression tendency (PDT)

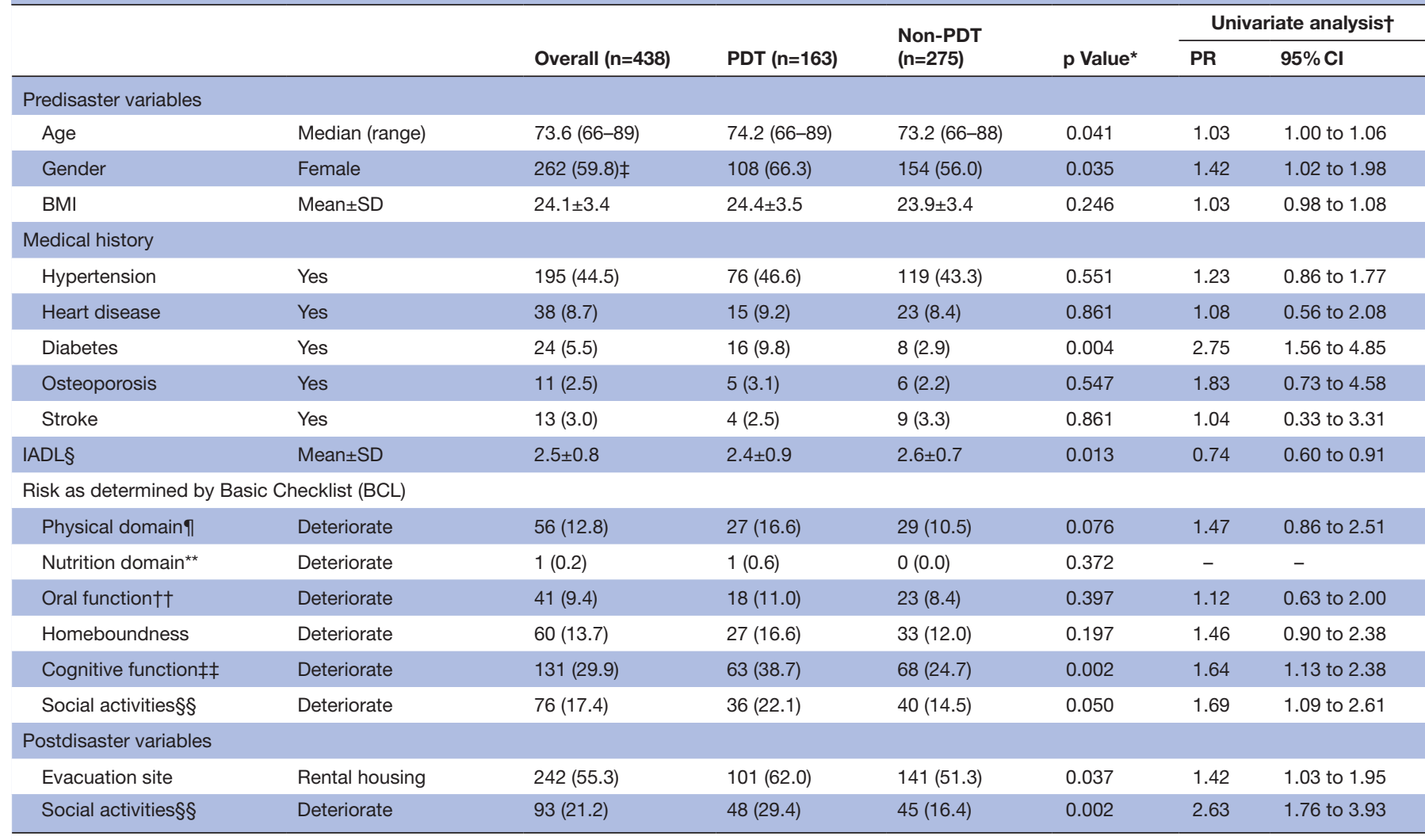

*The $\chi^{2}$ test was used for categorical variables; Student's t-test was used for continuous variables.

†Univariate analysis performed with objective (response) value taken as depression tendency occurrence $=1$ and non-depression tendency occurrence $=0$.

$\ddagger$ No. of persons (\%).

§Range and IADL score is 0 (poor) to 3 (favourable).

ๆ'Deteriorate' when $\geqq 3$ of 5 items apply.

**'Deteriorate' when 2 of 2 items apply.

††'Deteriorate' when $\geqq 2$ of 3 items apply.

抽Deteriorate' when $\geqq 1$ of 3 items apply.

$\S \S$ 'Deteriorate' when $\geqq 1$ of 2 items apply.

BMI, body mass index; IADL, instrumental activities of daily living; PDT, presence of depression tendency; PR, prevalenceratio. 


\section{Occurrence of depression tendency and related factors}

At follow-up, 163 participants (37.2\%) showed depression tendency (table 1). By question, 22.8\% said, "I have felt a lack of fulfilment in my daily life"; $17.1 \%$ said, "I have felt a lack of joy when doing things I used to enjoy"; $30.6 \%$ said, "I have felt difficulty in doing what I could do easily before"; 31.7\% said, "I have felt helpless"; and 32.6\% said, "I have felt tired without a reason".

Significantly more of the PDT group were female (66.3\% vs $56.0 \%$; $\mathrm{p}=0.035$; table 1$)$. The PDT group members (mean: 74.2 years) were significantly older than the non-PDT group members (73.2 years; $\mathrm{p}=0.041$ ). Diabetes was significantly more common among PDT group members $(p=0.004)$. IADL scores were significantly higher among non-PDT group members $(p=0.013)$. A significantly larger proportion of the PDT group requiring prevention or support for cognitive function $(p=0.002)$. The groups did not differ significantly in physical function, nutritional status, oral function or homeboundness.

PDT risk increased with age (PR 1.03; 95\% CI 1.00 to 1.06), female gender (PR 1.42; 95\% CI 1.02 to 1.98), history of diabetes (PR 2.75; 95\% CI 1.56 to 4.85 ) and cognitive function (PR 1.64; 95\% CI 1.13 to 2.38). It was significantly reduced by IADL (PR $0.74 ; 95 \%$ CI 0.60 to $0.91)$.

\section{Relationship between evacuation residence site and depression tendency}

PDT risk was significantly higher among participants living in rental accommodation than in purpose-built accommodation (crude PR 1.42; CI 1.03 to 1.95; adjusted PR 1.60; 95\% CI: 1.16 to 2.20; table 2).

By accommodation, $11.2 \%$ of participants in temporary accommodation and $18.6 \%$ in rental accommodation reported having no social activities where they lived. When social activities was added to the analysis, the risk for PDT in rental accommodation declined (adjusted PR $1.51 ; 95 \%$ CI 1.09 to 2.09$)$.

\section{DISCUSSION}

This study examined the incidence of depression and associated factors among elderly persons from Iitate village after the March 2011 earthquake in different living arrangements. We found that of the 438 respondents in the second survey, $163(37.2 \%)$ showed depression tendency. PDT risk was significantly increased by female gender, age, history of diabetes and cognitive disorder. It was significantly reduced by increased IADL. Engagement in social activities decreased PDT risk in rental accommodation.

\section{Changes in depression status that accompany evacuation}

To assess depression tendency, we conducted a follow-up survey of 2 years after the March 2011 earthquake disaster, examining individuals who showed no depression tendency before the earthquake. We found a $37.2 \%$ incidence of depression tendency. At follow-up, we found a $43.2 \%$ prevalence of depression tendency, a 12.5-point increase on the $30.7 \%$ prevalence measured in the same group before the earthquake, which is similar to the reference pre-earthquake value in neighbouring Miyagi Prefecture $(31.2 \%) .^{5}$ The result indicates an increasing depression tendency following the disaster. The proportion of affirmative responses to three of the five items examining depression tendency increased by $\geq 30 \%$ in the follow-up survey ('I have felt difficulty in doing what I could do easily before', 'I have felt helpless', 'I have felt tired without a reason'). This relatively large increase suggests that declining motivation, feelings of worthlessness and fatigue affected depression status.

On 31 March 2017, 19 of the 20 hamlets constituting Iitate village were reopened to habitation. However, many residents have been required to leave their chief occupations (eg, in primary production), and group and community activities were abruptly terminated following evacuation. Among all residents, $37.5 \%$ agreed with 'I feel that there is nothing pressing for me to do now, and I spend time idly' in October 2011, and 40.8\% agreed in June 2012 in whole village surveys. In the latter survey,

Table 2 Effects of evacuation site on postearthquake depression tendency by three-stage Poisson regression model

\begin{tabular}{|c|c|c|c|c|c|c|}
\hline \multirow[b]{2}{*}{ Factors } & \multicolumn{2}{|c|}{ First stage } & \multicolumn{2}{|c|}{ Second stage } & \multicolumn{2}{|c|}{ Third stage } \\
\hline & PR & $95 \% \mathrm{Cl}$ & PR & $95 \% \mathrm{Cl}$ & PR & $95 \% \mathrm{Cl}$ \\
\hline Evacuation site (rental housing) & 1.42 & 1.03 to 1.95 & 1.60 & 1.16 to 2.20 & 1.51 & 1.09 to 2.09 \\
\hline Gender (female) & & & 1.64 & 1.17 to 2.31 & 1.59 & 1.13 to 2.24 \\
\hline History of diabetes ('yes') & & & 3.24 & 1.78 to 5.89 & 3.25 & 1.80 to 5.86 \\
\hline Cognitive function (deteriorate) & & & 1.72 & 1.24 to 2.38 & 1.75 & 1.26 to 2.43 \\
\hline Social activities (deteriorate) & & & & & 1.55 & 1.07 to 2.23 \\
\hline
\end{tabular}

Poisson regression analysis was performed with objective (response) values taken as PDT occurrence $=1$ and non-PDT occurrence $=0$, and significant items in the univariate analysis as adjustment variables.

IADL, instrumental activities of daily living; PDT, presence of depression tendency; PR, prevalence ratio. 
this proportion increased with age: $35.6 \%$ of persons in their $20 \mathrm{~s}, 31.4 \%$ in their $40 \mathrm{~s}, 41.8 \%$ in their $60 \mathrm{~s}$ and $50.1 \%$ aged $\geq 70$ years. Thus, the follow-up survey and the village surveys indicate that depression tendency has increased with the passage of time after the earthquake and with increasing age. Elderly persons who suddenly lost their long-term homes experienced major psychological effects, perhaps magnified by the difficulty of adapting to novel circumstances in old age. Thus, elderly persons forced to live for long periods as evacuees owing to a technical disaster require reinforced psychological support and continued contact with friends.

Depression in elderly persons is sometimes overlooked; because psychological effects are often mistaken for cognitive disorders, emphasis on their physical state tends to divert attention away from possible depression. ${ }^{29}$ As such, appropriate screening needs to be made widely available. In addition, family members and friends should consult with specialist professionals if they sense physical or mental changes in elderly persons.

\section{Relationships between site of evacuation residence and depression status}

Compared with villagers who were evacuated in groups to purpose-built accommodation, those who were dispersed by evacuation into rental accommodation faced a higher risk of PDT and more commonly experienced social activities decline. The addition of social activities as an adjustment variable to the multivariate regression model moderately weakened the effect of residence type; this suggests that social factors account for at least part of this result. Each cluster of purpose-built accommodation has a 'self-administration committee' and a meeting hall, and consequent interpersonal contact. Conversely, renters have few opportunities to engage with fellow villagers, and tend to have less interpersonal contact. In addition, compared with persons living in purpose-built accommodation, renters more frequently responded that they have 'no one to communicate with' $(47.8 \%$ vs $24.6 \%)$. Prior studies in Japan and overseas have reported increased mortality risk, worsening physical health status and increased risk of depression among elderly people with insufficient individual and community-level social relationship. ${ }^{16-183031}$

In 2013, the Iitate village government began a café project for renters, and began providing opportunities for interactions using methods familiar to villagers, with emphasis on promoting autonomy, using community services available before the evacuation and carried out by villagers with government support. Since 2014, the café project has become more widespread in areas where relatively large numbers of evacuees live, thus underlining the importance of providing opportunities for villagers to interact with fellow villagers. It is expected to evaluate such newly implemented projects for enhancing social activities in the village and also for gaining further scientific investigation towards improved crisis preparedness.
Nonetheless, the effect of location remained significant despite this partial interjection of social activities into scattered sites (PR 1.51; table 2), even when the effect of social activities was adjusted for. This suggests the involvement of other intermediate variables. This may reflect risk awareness concerning radiation at the time the evacuation order was issued. In the survey of all villagers, some complained that evacuees were placed into purpose-built accommodation later (June-August 2011) than in other municipalities, and that temporary rental accommodation could have been found more quickly; others stated that although purpose-built accommodation was available within an hour's drive of the village, they sought rental accommodation further away, reflecting awareness of the dangers of radiation. Because high-risk awareness affects depression occurrence, ${ }^{32}$ awareness of the radiation risk may have contributed to postearthquake depression among the Iitate evacuees.

\section{Factors that promote depression associated with evacuation}

Among demographic variables, female gender, a history of diabetes, decline in IADL and cognitive disorder tendency each independently affected PDT risk. In the USA, women are twice as likely as men to suffer from major depression or dysthymia, and women changing homes or cultures show higher propensity to depression than women not undergoing such changes. ${ }^{33}$ The relationship between such changes and depression is likely to be similar in Japan.

Our study is consistent with research that has identified a medical history of diabetes and IADL decline as depression risk factors. ${ }^{34-37}$ In our results, a history of diabetes was most strongly correlated with depression tendency. In a meta-analysis of 39 studies that examined diabetes and depression, $11.4 \%$ of patients with diabetes had complications of depression and $31.0 \%$ were suspected of having co-occurring depression. ${ }^{38}$ Diabetes treatments include diet management, exercise and medicinal regimens; however, evacuees commonly have difficulty obtaining food, have reduced opportunities to exercise and face changes in their medicinal regimen. Situations that prevent or disrupt typical ADL appear to promote depression. ${ }^{39}$ The unpredictable life of an evacuee limits individuals' opportunities to leave their homes and go outside, even to go shopping for daily necessities. Evacuation also disrupts evacuees' social networks: friends who were able to see one another in person before evacuation might now live far apart. These factors combine to complicate the process of following a diabetes treatment plan. Among patients with diabetes, depression reduces compliance with self-care (ie, diet and exercise) and worsens blood sugar management. It is therefore essential that mental health support be provided for patients with diabetes after a technical disaster.

In our initial survey, $29.9 \%$ of respondents required cognitive disorder prevention or support. This was the highest risk ascertained with the BCL. Although this value was lower than the pre-earthquake reference value 
in neighbouring Miyagi Prefecture $(39.5 \%),{ }^{23}{ }^{25}$ it was 10 points higher in the PDT group $(38.7 \%)$ than in the non-PDT group $(24.7 \%)$, indicating a strong relationship with depression tendency. Nonetheless, depression manifestations are similar to symptoms of early-stage elderly cognitive disorder (pseudodementia), potentially impeding differential diagnosis. ${ }^{40}$ It is therefore necessary to recognise that predisaster needs for cognitive disorder prevention and support become risks for the occurrence of depression following a disaster.

\section{Limitations and strengths}

Our study has the following limitations. First, because the survey was conducted during a village-wide, government-conducted, general health check-up, residents evacuated to distant sites did not participate. Although we surmised that many residents who evacuated to areas outside the prefecture face anxieties, we were unable to examine their depression tendencies. In addition to this, because the first survey was designed by the local municipality, it did not include certain important variables related to depression such as marital status (including bereavement) and employment (including loss of job due to the evacuation). Also, the effects of the disaster including fear of exposing radiation are not included.

Nonetheless, the study used data collected before and after the disaster forced the whole village to evacuate, and the response rate was high owing to the participation of the local municipality. Therefore, the data are likely to reflect the characteristics of the affected areas and such health monitoring of evacuees can be applied in the event of a future radiation disaster in another region.

\section{Author affiliations \\ ${ }^{1}$ Department of Public Health, School of Medicine, Fukushima Medical University, Fukushima, Japan \\ ${ }^{2}$ Department of Public Health and Welfare, litate Village, Fukushima, Japan \\ ${ }^{3}$ Tokyo Metropolitan Institute of Gerontology, Tokyo, Japan \\ ${ }^{4}$ Center for Integrated Science and Humanities, Fukushima Medical University, \\ Fukushima, Japan \\ ${ }^{5}$ International Community Health, Graduate School of Medicine, Fukushima Medical University, Fukushima, Japan \\ ${ }^{6}$ Department of Medical Psychology, Graduate School of Medical Sciences, Kitasato University, Kanagawa, Japan}

Contributors YK, HI, AG, KY, KM, Yl and YS conceptualised and designed the study. YK and KM contributed to date collection and quality control. YK conducted the analysis and wrote the manuscript. All authors read and approved the final version of the manuscript.

Funding This work was supported by JSPS KAKENHI Grant Number 15K17296.

Competing interests None declared.

Patient consent Obtained.

Ethics approval The Ethics Committee of Fukushima Medical University granted its consent (Examination № 2609).

Provenance and peer review Not commissioned; externally peer reviewed. Data sharing statement No additional data are available.

Open Access This is an Open Access article distributed in accordance with the Creative Commons Attribution Non Commercial (CC BY-NC 4.0) license, which permits others to distribute, remix, adapt, build upon this work non-commercially, and license their derivative works on different terms, provided the original work is properly cited and the use is non-commercial. See: http://creativecommons.org/ licenses/by-nc/4.0/

(c) Article author(s) (or their employer(s) unless otherwise stated in the text of the article) 2017. All rights reserved. No commercial use is permitted unless otherwise expressly granted.

\section{REFERENCES}

1. Ohtsuru A, Tanigawa K, Kumagai A, et al. Nuclear disasters and health: lessons learned, challenges, and proposals. Lancet 2015;386:489-97.

2. Ochi S, Murray V, Hodgson S. The great East Japan earthquake disaster: a compilation of published literature on health needs and relief activities, march 2011-september 2012. PLoS Curr 2013;5.

3. Hasegawa A, Tanigawa K, Ohtsuru A, et al. Health effects of radiation and other health problems in the aftermath of nuclear accidents, with an emphasis on Fukushima. Lancet 2015;386:479-88.

4. Yasumura S. Suggestion - toward the future - measures to be taken. In public health in a nuclear disaster. In: Yasumura S, Kamiya K, eds. Message from Fukushima. Hiroshima University Press, 2016.

5. Tomata Y, Suzuki Y, Kawado M, et al. Long-term impact of the 2011 Great East Japan Earthquake and tsunami on functional disability among older people: a 3-year longitudinal comparison of disability prevalence among Japanese municipalities. Soc Sci Med 2015;147:296-9.

6. Kinley DI. Chernobyl's legacy: Health, environmental and socioeconomic impacts and recommendations to the Governments of Belarus, the Russian Federation and Ukraine. The Chernobyl Forum. 2005 http://www.iaea.org/inis/collection/NCLCollectionStore/_Public/ 36/093/36093263.pdf

7. Bromet EJ. Mental health consequences of the Chernobyl disaster. $J$ Radiol Prot 2012;32:N71-N75.

8. Ursano RJ, McCaughey BG, Fullerton CS. eds. Individual and community responses to Trauma and disaster. Cambridge: Cambridge University Press, 1994.

9. Havenaar JM, Rumyantzeva GM, van den Brink W, et al. Long-term mental health effects of the Chernobyl disaster: an epidemiologic survey in two former Soviet regions. Am J Psychiatry 1997;154:1605-7.

10. Norris SL, Nichols PJ, Caspersen CJ, et al. The effectiveness of disease and case management for people with diabetes. A systematic review. Am J Prev Med 2002;22:15-38.

11. Yokoyama Y, Otsuka K, Kawakami N, et al. Mental health and related factors after the Great East Japan earthquake and tsunami. PLoS One 2014;9:e102497.

12. Hikichi $\mathrm{H}$, Aida J, Kondo K, et al. Increased risk of dementia in the aftermath of the 2011 Great East Japan Earthquake and Tsunami. Proc Natl Acad Sci U S A 2016. [Epub ahead of print 24 Oct 2016].

13. Norris FH, Friedman MJ, Watson PJ, et al. 60,000 disaster victims speak: Part I. An empirical review of the empirical literature, 19812001. Psychiatry 2002;65:207-39.

14. Suzuki Y, Yabe H, Yasumura S, et al. Psychological distress and the perception of radiation risks: the Fukushima health management survey. Bull World Health Organ 2015;93:598-605.

15. Fussell E, Lowe SR. The impact of housing displacement on the mental health of low-income parents after Hurricane Katrina. Soc Sci Med 2014:113:137-44.

16. Harlow SD, Goldberg EL, Comstock GW. A longitudinal study of risk factors for depressive symptomatology in elderly widowed and married women. Am J Epidemiol 1991;134:526-38.

17. Oxman TE, Berkman LF, Kasl S, et al. Social support and depressive symptoms in the elderly. Am J Epidemiol 1992;135:356-68.

18. Hashimoto $\mathrm{K}$, Kurita $\mathrm{H}$, Haratani $\mathrm{T}$, et al. Direct and buffering effects of social support on depressive symptoms of the elderly with home help. Psychiatry Clin Neurosci 1999;53:95-100.

19. Koyama S, Aida J, Kawachi I, et al. Social support improves mental health among the victims relocated to temporary housing following the Great East Japan Earthquake and Tsunami. Tohoku J Exp Med 2014;234:241-7.

20. Long D, Wong YL. Time bound: the timescape of secondary trauma of the surviving teachers of the Wenchuan Earthquake. $A m \mathrm{~J}$ Orthopsychiatry 2012;82:241-50.

21. litate Village. litate-sonmin no Hinanseikatsujittai oyobi Kisonikoutou ni kansuru enquete-chousa (Report of a 2012 whole village survey), 2012. http://www.vill.iitate.fukushima.jp/saigai/wp-content/uploads/ 2012/06/27fe90c68dfcd08ecba20a8a13176e07.pdf

22. Matsuno M, Chiba E. litate-mura wa makenai: tsuchi to hito no mirai no tame ni (litate village will not give up: For the future of humanity and the native soil). Tokyo: Iwanami Shoten, 2012. 
23. Satake S, Senda K, Hong YJ, et al. Validity of the Kihon Checklist for assessing frailty status. Geriatr Gerontol Int 2016;16:709-15.

24. Arai H, Satake S. English translation of the Kihon Checklist. Geriatr Gerontol Int 2015;15:518-9.

25. Tomata Y, Hozawa A, Ohmori-Matsuda K, et al. Verification of predictive validity of Kihon Checklist regarding occurrence of long-term certification requirement over a 1-year period. Ohsaki Cohort Study 2006. Japanese Society of Public Health Magazine, 2011:58:3-13.

26. Fujisawa D, Tanaka E, Sakamoto S, et al. The development of a brief screening instrument for depression and suicidal ideation for elderly: the Depression and Suicide Screen. Psychiatry Clin Neurosci 2005;59:634-8.

27. Suzuki N, Makigami K, Goto A, et al. Comparison of ability-based and performance base IADL evaluation of community-dwelling elderly using the Kihon Checklist and TMIG Index of Competence. Jpn J Geriatr 2007;44:619-26.

28. Kera $\mathrm{T}$, Kawai $\mathrm{H}$, Yoshida $\mathrm{H}$, et al. Classification of frailty using the Kihon checklist: a cluster analysis of older adults in urban areas. Geriatr Gerontol Int 2017;17:69-77.

29. Gelenberg A. Depression is still underrecognized and undertreated. Arch Intern Med 1999;159:1657-8.

30. Berkman LF, Syme SL. Social networks, host resistance, and mortality: a nine-year follow-up study of Alameda County residents. Am J Epidemiol 1979;109:186-204.

31. Matsuyama Y, Aida J, Hase A, et al. Do community- and individuallevel social relationships contribute to the mental health of disaster survivors? a multilevel prospective study after the Great East Japan Earthquake. Soc Sci Med 2016;151:187-95.
32. Imai H, Okumiya K, Fukutomi E, et al. Association between risk perception, subjective knowledge, and depression in communitydwelling elderly people in Japan. Psychiatry Res 2015;227:27-31.

33. U.S. National Institute of Health. Task Force on the NIH Women's Health Research Agenda for the 21st Century. Agenda for Research on Women's Health for the 21st Century: without special title. 1999.

34. Cole MG, Dendukuri N. Risk factors for depression among elderly community subjects: a systematic review and meta-analysis. $\mathrm{Am} \mathrm{J}$ Psychiatry 2003;160:1147-56.

35. Farmer ME, Locke BZ, Mościcki EK, et al. Physical activity and depressive symptoms: the NHANES I Epidemiologic Follow-up Study. Am J Epidemiol 1988;128:1340-51.

36. Jiang J, Tang Z, Futatsuka M. The impact of ADL disability on depression symptoms in a community of Beijing elderly, China. Environ Health Prev Med 2002;7:199-204.

37. Berkman LF, Berkman CS, Kasl S, et al. Depressive symptoms in relation to physical health and functioning in the elderly. Am J Epidemiol 1986;124:372-88.

38. Shimada K, Yamazaki S, Nakano K. Association between family social support and depression status in the elderly: 5-year community-based prospective cohort study. Japanese Journal of Gerontology 2012;34:350-9.

39. Anderson RJ, Freedland KE, Clouse RE, et al. The prevalence of comorbid depression in adults with diabetes: a meta-analysis. Diabetes Care 2001;24:1069-78.

40. Alexopoulos GS. Depression in the elderly. Lancet 2005; 365:1961-70. 